Pure Appl. Chem., Vol. 81, No. 11, pp. 1991-2000, 2009.

doi:10.1351/PAC-CON-08-11-02

(c) 2009 IUPAC, Publication date (Web): 15 October 2009

\title{
Development of efficient processes under flow conditions based on catalysts immobilized onto monolithic supported ionic liquid-like phases*
}

\author{
M. Isabel Burguete, Eduardo García-Verdugo $¥$, Naima Karbass, \\ Santiago V. Luis ${ }^{\ddagger}$, Victor Sans, and Maia Sokolova

\begin{abstract}
Department of Inorganic and Organic Chemistry, A.U. for Advanced Organic Materials, University Jaume I/CSIC, Avda. Sos Baynat s/n. E-12071 Castellón, Spain
\end{abstract}

\begin{abstract}
The introduction of imidazolium subunits into polystyrene-divinylbenzene (PS-DVB) polymers enables the preparation of a variety of catalytic systems. Those include the stabilization of catalytically active Pd nanoparticles (PdNPs), immobilized enzymes, and basic catalysts. The use of monolithic supports having the appropriate morphological properties is greatly advantageous for the development of efficient catalytic processes under flow conditions based on those systems. On the other hand, the combination of those supported catalytic systems and flow conditions can be further implemented, in terms of green chemistry, by the substitution of the use of traditional solvents by environmentally friendly conditions such as the use of supercritical fluids (SCFs).
\end{abstract}

Keywords: flow chemistry; functional polymers; green chemistry; Heck reaction; ionic liquids; supercritical liquids; supported biocatalysts; supported catalysts.

\section{INTRODUCTION}

Ionic liquids (ILs) have emerged as a key resource for the substitution of traditional organic solvents in chemical processes in order to achieve more environmentally benign conditions [1-4]. Many different applications have been developed from ILs as they are excellent "green" solvents with significant potential for both synthesis and separation of chemicals. In the case of chemical transformations, they are both suitable solvents and immobilizing phases to develop liquid/liquid biphasic systems for a number of catalyzed reactions [4]. In this regard, the use of ILs for a given chemical transformation can significantly affect the corresponding outcome, as the thermodynamics and kinetics of the reactions carried out in ILs can be different from those in conventional molecular solvents. Nevertheless, there are several drawbacks associated with the use of ILs. Although ILs have become commercially available, they are still relatively expensive compared to traditional solvents. Besides, some of them show evidence of low biodegradability and (eco)toxicological properties [5]. Hence, the immobilization of ILs onto a support or structured material is a highly attractive strategy to minimize the amount of ILs used, avoiding, at the same time, any toxicological concern. Thus, the use of IL-like functionalities as modifiers of different supports is highly interesting, since, ideally, they will tune the nature of the material, transferring

\footnotetext{
*Paper based on a presentation at the $2^{\text {nd }}$ International Conference on Green Chemistry (ICGC-2), 14-20 September 2008, Moscow, Russia. Other presentations are published in this issue, pp. 1961-2129.

‡Corresponding authors: E-mail: luiss@ qio.uji.es (S. V. Luis); eduardo.garcia-verdugo@qio.uji.es (E. García-Verdugo).
} 
the IL properties at molecular and nanoscale level [6]. The resulting materials could present many of the characteristics and properties of ILs as molecular solvents. Two different approaches have been explored for the preparation of such materials: the adsorption of a thin film of an IL onto an adequate surface, mainly polar silica or inorganic materials [7-10], and the covalent anchoring of functional moieties with IL-like structure [11-16].

On the other hand, the greenness of chemical transformations is also closely related to the use of catalytic and engineering approaches [17]. In this regard, the advantages of the use of catalytic reactions instead of stoichiometric transformations are clear, but we need to bear in mind that the substitution of batch processes by flow conditions is also a significant improvement. The use of flow conditions allows for employing smaller and more flexible equipment, facilitates process intensification increasing space-time yields, reduces risks and environmental impacts, and favors automatization and development of integrated processes [18]. Monolithic materials are very well suited for the development of processes under flow conditions using immobilized reagents and catalysts. In this regard, monolithic polymers, in particular those derived from polystyrene-divinylbenzene (PS-DVB) can be easily prepared, in a variety of shapes and morphological properties, and have chemical properties compatible with the preparation of a large variety of supported reagents and catalysts. The usefulness of this approach has been illustrated in our group for different applications, including enantioselective transformations [19-27]. One additional advantage of this kind of material, taking into consideration the principles of green chemistry, is that they can also be tested using supercritical fluids (SCFs) as the solvent or under solventless conditions [26,27].

Here, we describe our strategy for the immobilization of IL moieties onto a structured monolithic material by covalent linking, transferring the IL properties to the solid phase, and leading to the preparation of monolithic supported ionic liquid-like phases ( $m$-SILLPs). The preparation of different catalytic systems based on SILLPs has allowed us to: (i) minimize the amount of ILs used, (ii) improve separation and recyclability, (iii) develop mini-flow reactors, and (iv) develop continuous processes in SCFs. Those SILLPs have been used to immobilize the required catalysts for different processes, ranging from basic catalysts or Pd nanoparticles (PdNPs) for $\mathrm{C}-\mathrm{C}$ coupling reactions ncEtOH to enzymes for biocatalytic process in $\mathrm{scCO}_{2}$. It must be noted that, in most cases, with the use of SCFs, the former catalysts have shown a better performance than that obtained in flow systems using conventional organic solvents.

\section{RESULTS AND DISCUSSION}

\section{Synthesis and characterization of $m$-SILLPs}

The preparation of the polymeric monolithic materials is depicted in Scheme 1. The monolithic polymers $(\boldsymbol{m}-\mathbf{3})$ were synthesized by thermally induced radical solution polymerization of a monomeric mixture of $p$-chloro-methylstyrene (1) and divinylbenzene (2), using toluene/1-dodecanol as the precipitating porogenic mixture and azobisisobutyronitrile (AIBN) as the radical initiator. In order to take full advantage of the potential of those monolithic systems, polymerization was carried out within stainless steel columns, which can be adapted to be used as mini-flow reactors ( $1 \mathrm{ml}$ volume) under flow conditions (see Fig. 1). $m$-SILLPs $\mathbf{4 a - b}$ were obtained by the reaction of $\boldsymbol{m} \mathbf{- 3}$ with $N$-butyl imidazole or $\mathrm{N}$-methyl imidazole. The introduction of the imidazolium IL-like moieties can be monitored through the disappearance of the $\mathrm{CH}_{2}-\mathrm{Cl}$ group by using both Fourier transform-infrared (FT-IR) Raman spectroscopy and a colorimetric method based on the [4-(4-nitrobenzyl)pyridine] (NBP) test [28-30]. A $95 \%$ conversion of the chloromethyl groups was achieved after $5 \mathrm{~h}$ of reaction. Longer reaction times did not improve the conversion degree. Most likely, a small percentage of $\mathrm{CH}_{2}-\mathrm{Cl}$ groups are located in non-accessible highly cross-linked regions. The FT-Raman of $m$-SILLP-4 showed bands characteristic of 1-alkyl-3-(4-vinylbenzyl)-imidazolium chloride $\left(1505,1345,1078\right.$, and $\left.1029 \mathrm{~cm}^{-1}\right)$. The loading for $m$-SILLP-4a was found to be, by elemental analysis, $1.98 \mathrm{mmol}$ of imidazolium units per gram of 


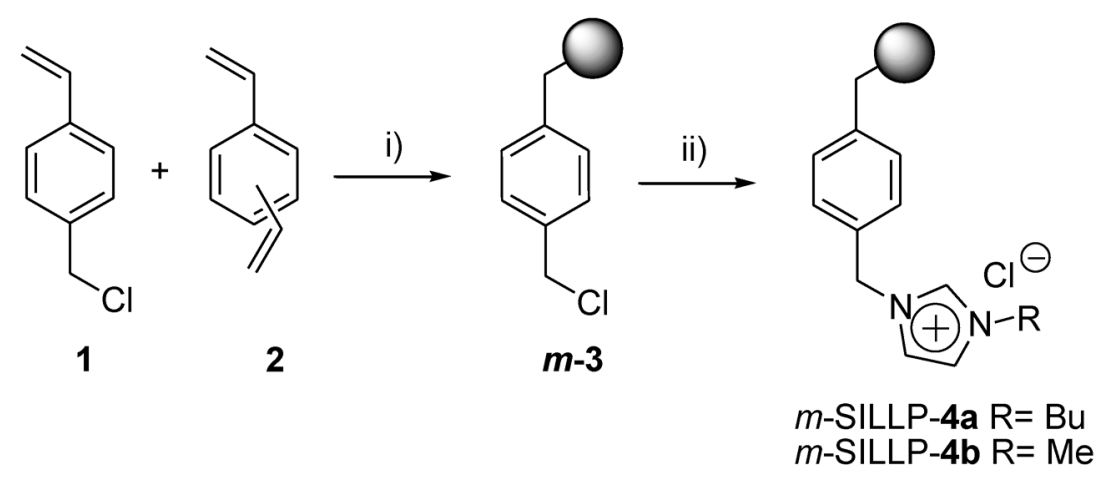

Scheme 1 General procedure for the synthesis of $m$-SILLPs.

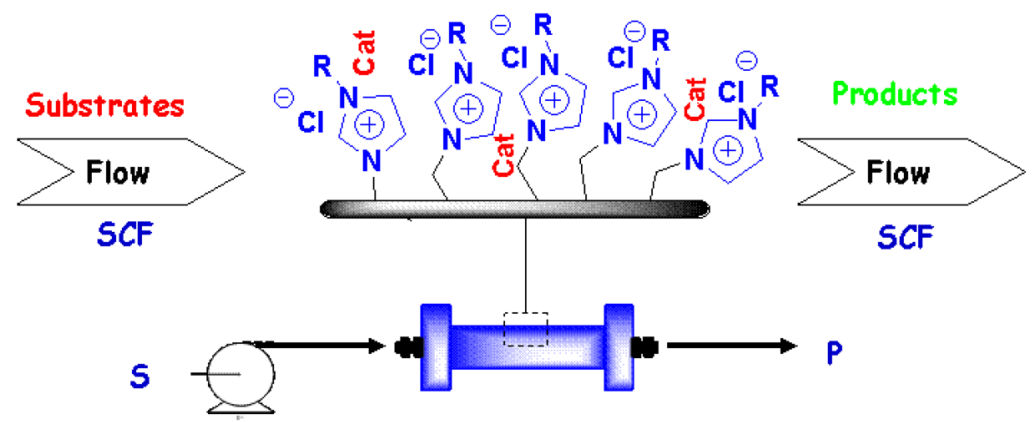

Fig. 1 Catalysts immobilized onto $m$-SILLPs for flow processes.

polymer, which is equivalent to $54.7 \%$ by weight. Additionally, the introduction of other counteranions can be easily carried out by the metathesis reaction of the chloride anion with the corresponding salts or acid reactants $\left(\mathrm{NaBF}_{4}, \mathrm{CF}_{3} \mathrm{SO}_{3} \mathrm{H}, \mathrm{NaSbF}_{6}, \operatorname{LiNTf}_{2} \ldots\right)$. The anion exchange can be followed by FT-IR and Raman spectroscopy, as well as by X-ray photoelectron spectroscopy (XPS) analysis. All spectroscopic data are in good agreement with those obtained for the corresponding bulk ILs such as benzyl methyl imidazolium chloride or benzyl butyl imidazolium chloride. Thus, for instance, XPS data provide energy values that are essentially identical to those found for related ILs such as $\left[\mathrm{C}_{2} \mathrm{MIM}\right][\mathrm{X}]$.

The introduction of the imidazolium subunits dramatically modifies the microenvironment at the monolith surfaces. This was illustrated by measuring the solvatochromic effects experienced by a fluorescent probe, such as pyrene. The ratio of the intensities for two emission bands of pyrene $\left(I_{\mathrm{I}} / I_{\mathrm{III}}\right)$ is a classical measurement for the polarity of a given medium [31]. When applied for $m$-SILLPs-4a-b the $\mathrm{I}_{\mathrm{I}} / \mathrm{I}_{\mathrm{III}}$ values were 1.34 and 1.42 , respectively, providing an estimation of polarity comparable to that of methanol $\left(I_{\mathrm{I}} / I_{\mathrm{III}}=1.33\right)$. Those values are significantly higher than the one measured for $\boldsymbol{m} \mathbf{- 3}$, clearly indicating a completely different microenvironment on the surfaces of SILLPs. This value is sensitive to the different structural factors present in the imidazolium unit, such as the nature of the alkyl chain and that of the counteranion and similar to that observed in methanol (II/IIII $=1.33$ ) [32]. From those measurements, a rough empirical estimation of polarity $(\varepsilon)$ gave values of 10-20 for SILLPs, in good agreement with the values reported for ILs (i.e., 15.76 for $\left.\left[\mathrm{C}_{2} \mathrm{MIM}\right]\left[\mathrm{NTf}_{2}\right]\right)$. Similar trends have been observed using other solvatochromic probes such as the Reichardt's probe.

As mentioned above, those macroporous polymers are designed to be used in flow-through mode. Therefore, they need to be materials with a low flow resistance. We could determine that the monolithic columns obtained had similar structural and morphological properties as similar materials that have been used for chromatographic applications and for other catalytic applications [33]. They also showed 
the capacity to work properly under supercritical conditions, according to the initial design. Thus, Fig. 2 shows that for polymer $m$-SILLP-4a the back pressure (normalized to a length of $1 \mathrm{~cm}$ ) was lower than $0.2 \mathrm{MPa} / \mathrm{cm}$ for different flow rates $\left(0.1-3.5 \mathrm{ml} / \mathrm{min}\right.$ of $\left.\mathrm{CO}_{2}\right)$, temperatures, and pressures, confirming the low pressure drop of this monolithic bed to work as flow reactor under high pressure.

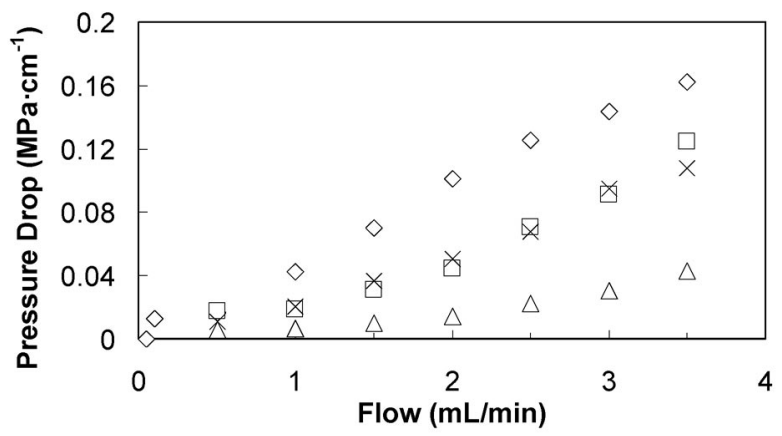

Fig. 2 Pressure drop $(\Delta P, \mathrm{MPa} / \mathrm{cm})$ for $m$-SILLP-4a (normalized to a length of $1 \mathrm{~cm}) \mathrm{vs}$. $\mathrm{CO}_{2}$ flow rate $(\mathrm{ml} / \mathrm{min})$ $\left[(\diamond) 40{ }^{\circ} \mathrm{C}, 8 \mathrm{MPa}, \rho=0.311 \mathrm{~g} / \mathrm{ml} ;(\square) 100{ }^{\circ} \mathrm{C}, 10 \mathrm{MPa}, \rho=0.191 \mathrm{~g} / \mathrm{ml} ;(\triangle) 100{ }^{\circ} \mathrm{C}, 15 \mathrm{MPa}, \rho=0.336 \mathrm{~g} / \mathrm{ml} ;(\times)\right.$ $\left.100{ }^{\circ} \mathrm{C}, 8 \mathrm{MPa}, \rho=0.143 \mathrm{~g} / \mathrm{ml}\right]$.

Thus, those initial studies not only revealed the easy preparation of the corresponding SILLPs with the appropriate morphology, but revealed how the macroscopic properties of ILs are transferred to the functional surfaces of the corresponding functional polymers. Once the mini-flow reactors were prepared, we proceeded to the immobilization of the different catalytic systems. For this purpose, three different categories of catalysts were considered: (i) Pd- $N$-heterocyclic carbene (NHC) complexes or PdNPs; (ii) biocatalysts such as Candida antarctica lipase B (CALB) enzymes; and (iii) basic catalysts.

\section{Catalytic systems based on $\boldsymbol{m}$-SILLPs}

\section{Catalytic $C-C$ coupling reactions based on supported $P d$ species}

Supported Pd-based catalysts were prepared using two different strategies as shown in Scheme 2 starting from $m$-SILLPs 4. Exchange of the $\mathrm{Cl}^{-}$counteranion in $\mathbf{4}$ by $\mathrm{PdCl}_{4}^{-}$to afford 5 was carried out using $\mathrm{PdCl}_{3}$ or under acidic conditions $(\mathrm{HCl})$. A variety of reductors were able to reduce those $\mathrm{Pd}^{2+}$ complexes to $\operatorname{Pd}(0)$ with the formation of PdNPs on the surfaces of the monoliths (polymers 6 ). In the second approach, the use of $\operatorname{Pd}(\mathrm{OAc})_{2}$ under basic conditions afforded the corresponding supported Pd-NHC carbenes 7. Nevertheless, under all the reaction conditions studied, reduction of the Pd-NHC carbenes (7) to PdNPs (6) was observed to take place. Scanning electron microscopy (SEM) and electron probe microanalysis revealed the presence of well-dispersed Pd metal particles. It is noteworthy that the final $\operatorname{Pd}(0)$ loading of the catalyst $(0.21$ mequiv $\mathrm{Pd} / \mathrm{g}$ polymer $)$ was kept much lower than the methyl-imidazolium content (3.07 mequiv imidazolium/g polymer ca. 15:1 imidazolium:Pd ratio). This is important as the mechanism for those reactions seems to occur through the participation of soluble catalytic species [34], and a key role of the surface of the SILLPs is to recapture those species at the end of the reaction, under a "release and catch" mechanism, to avoid Pd-leaching and permit the reuse and the application of continuous flow conditions. A large excess of imidazolium subunits was observed to favor this strategy. 


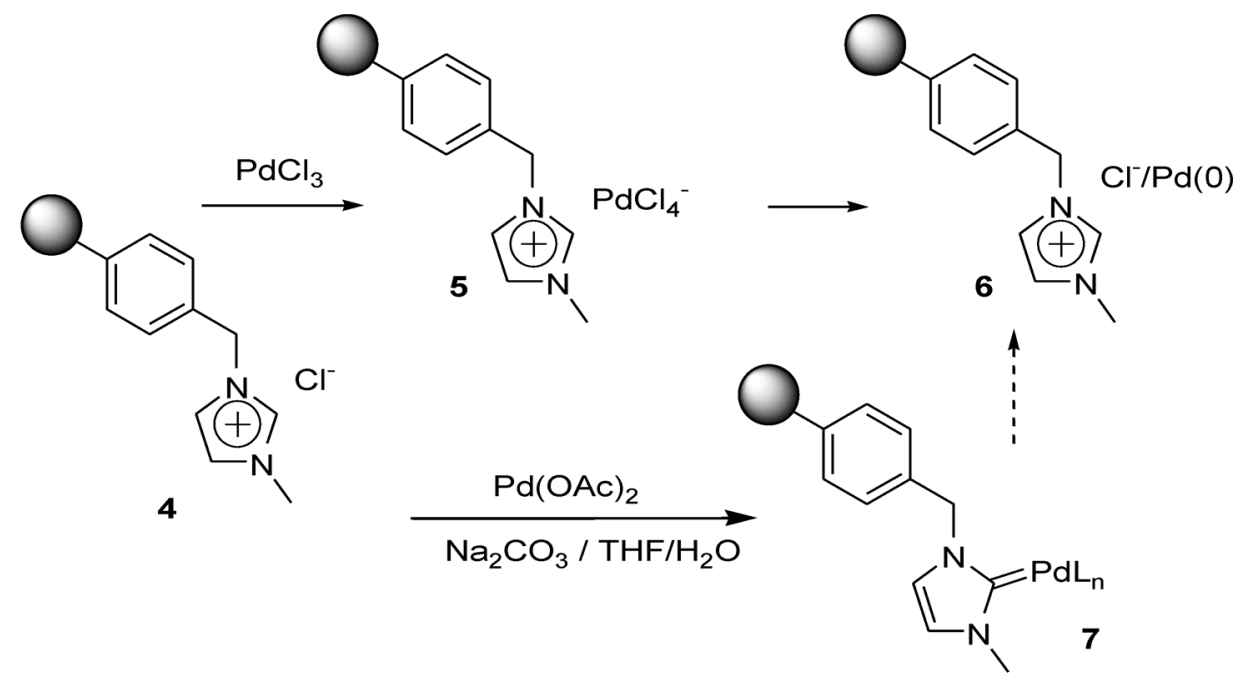

Scheme 2 Preparation of supported Pd species.

The first assays were carried out under flow conditions using dimethylformamide (DMF) as the solvent for the Heck reaction between iodobenzene and methyl acrylate and confirmed the potential of resins 6 as Pd catalytic systems (Scheme 3). The catalytic microreactor was stable for more than 13 $\mathrm{h}$ (ca. 170 bed volumes) giving place to the formation $100 \%$ of the corresponding trans styrene 10a and no leaching of Pd [35].

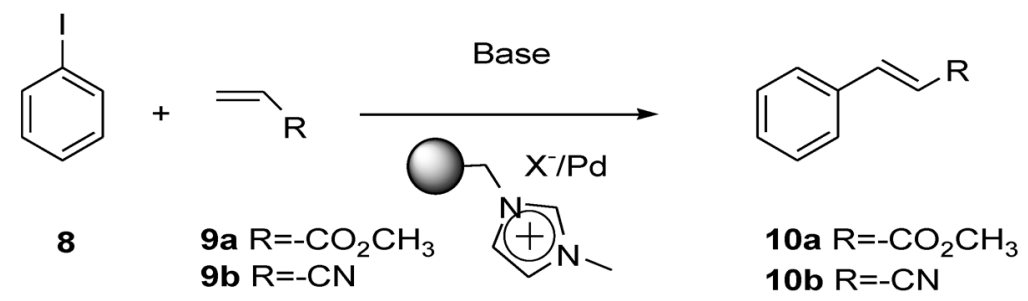

Scheme 3 General Heck process using Pd-supported species.

One important limitation of the process studied is the need to use DMF as the solvent. This limitation is common to other reported efforts toward the development of continuous flow systems for $\mathrm{Pd}$-catalyzed $\mathrm{C}-\mathrm{C}$ bond formation [36,37]. All of them require the use of conventional organic solvents either for the reaction or for the extraction of the product. In the search for more environmentally friendly protocols, the use of SCFs was considered. Hot pressurized ethanol can be a good alternative solvent. Ethanol is not only benign, easily available, and relatively cheap, it is also a solvent whose properties are easily adjustable with $P$ and $T$. Supercritical ethanol provides a less corrosive solvent and with more accessible critical parameters $\left(T_{\mathrm{c}}=516 \mathrm{~K}, P_{\mathrm{c}}=6.4 \mathrm{MPa}, \rho_{\mathrm{c}}=0.276 \mathrm{~g} \mathrm{~cm}^{-1}\right)$ than $\mathrm{scH}_{2} \mathrm{O}$. Therefore, it can be seen as a noncorrosive, low-pressure $\mathrm{scH}_{2} \mathrm{O}$ equivalent. One can also expect a pronounced enhancement of the solubility of some substances, compared with $\mathrm{CO}_{2}$, due to the hydrogenbonding ability of the former.

When near-critical EtOH was used, reduction of $\mathrm{Pd}^{2+}$-supported precursors to PdNPs took place directly without the need of using any additional reducing agent. The optimization of the reaction conditions for the benchmark Heck reaction (Scheme 3) was systematically investigated by varying tem- 
perature, pressure, and flow rate. In general, temperatures higher than $150{ }^{\circ} \mathrm{C}$ were required to achieve significant yields of trans-methylcinnamate. The reaction did not take place in ethanol at atmospheric pressure and $90{ }^{\circ} \mathrm{C}$. Conversions of 8 into 9 a reached $85 \%$ at $200{ }^{\circ} \mathrm{C}$ and $8 \mathrm{MPa}$, leading again to $100 \%$ selectivity for the trans isomer and no Pd leaching [38]. It is worth mentioning that temperatures higher than $250{ }^{\circ} \mathrm{C}$, which could allow working under true supercritical conditions, led to transesterification of methyl cinnamate to the corresponding ethyl cinnamate. Thus, our results clearly revealed that it is possible to develop highly stable and efficient $\operatorname{Pd}(0)$ catalysts supported onto polymeric monoliths containing IL-like units (Pd-m-SILLPs). Those catalysts show a good activity and stability under continuous flow conditions. The reaction does not require the use of an inert atmosphere, as it is typical for these processes. The presence of IL-like units seems to play an important role in capturing and stabilizing the soluble Pd active species that can mediate the transformation. Finally, the catalytic materials here presented allow the substitution of classical solvents such as DMF by more benign solvents like near-critical ethanol.

\section{Bioreactors based on monolithic supported IL-like phases}

A very different catalytic system was obtained by supporting a CALB on $m$-SILLPs 4 (Fig. 3). The immobilization of the enzyme was performed by simple adsorption from an aqueous solution of CALB. The resulting enzymatic catalysts ( $m$-SILLP-11-CALB) showed a very large IL/enzyme ratio, which ensured a full interaction between both enzyme and protein molecule and the IL phase, and could favor the enzyme stabilization [39]. $m$-SILLPs not only provide high flow characteristics and mechanical stability, based on the intrinsic properties of these macroporous materials, but also an easy and simple protocol to anchor the enzyme onto a modified matrix with "enzyme-friendly" moieties like alkyl-imidazolium cations.

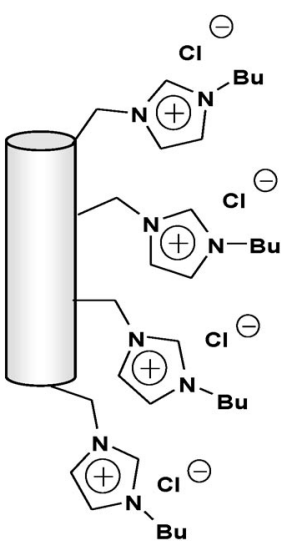

4
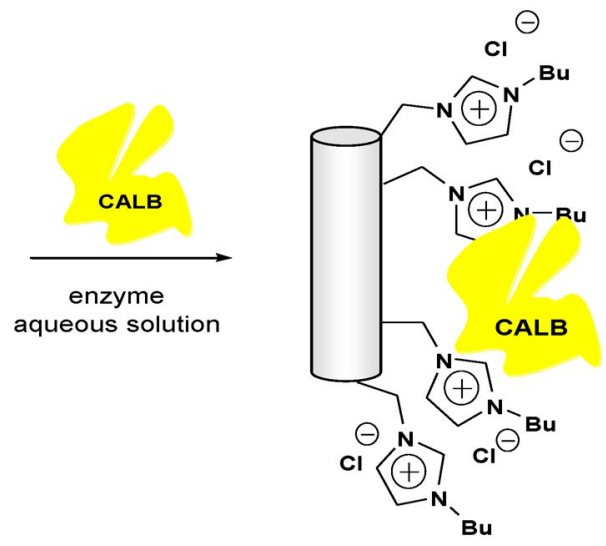

11

Fig. 3 Preparation of immobilized enzyme derivatives by simple adsorption of an aqueous solution of CALB onto m-SILLPs. 4: $1.98 \mathrm{mmol} \mathrm{IL/g} \mathrm{(54.7 \%} \mathrm{w/w);} \mathrm{mean} \mathrm{pore} \mathrm{diameter} \mathrm{for} \mathrm{the} \mathrm{monolith} 1 \mu \mathrm{m} .11: 0.31 \mu \mathrm{mol}$ enzyme/g; IL/enzyme ratio 6387.

The ability of $m$-SILLPs-CALB 11 to catalyze transesterification reactions in $\mathrm{scCO}_{2}$ was tested by using the synthesis of citronellyl propionate $\mathbf{1 4}$ as the benchmark activity test (Scheme 4). Table 1 summarizes some of the results found [40]. It can be seen that for all the immobilized derivatives, the productivity in the synthetic process was increased with temperature, reaching the maximum level at $80{ }^{\circ} \mathrm{C}$, and then decreasing for $100{ }^{\circ} \mathrm{C}$. Temperature seems to be a clear activating parameter for the enzymatic catalysis, although in the case of $\mathrm{scCO}_{2}$, a decrease in the fluid density has also been described as a positive parameter in enzyme activity. Those results should be analyzed as a function of both the 
mass transport of the substrates to the active sites and the ability of the support to provide an appropriate microenvironment for the enzyme. Thus, for example, the large pore distribution of the original $m$-SILLPs-4 is not affected by the immobilization of the enzyme, no pressure drop being observed. This, together with the high efficiency of $\mathrm{scCO}_{2}$ to transport hydrophobic compounds, ensures very fast mass transfer. On the other hand, ILs have been described as very efficient liquid supports for the immobilization of biocatalysts, for multipoint enzyme-IL interactions (ionic, hydrogen bonding, van der Waals, etc.) may occur, resulting in a supramolecular network able to maintain the active protein conformation even at high temperatures. In our case, monoliths $\mathbf{1 1}$ not only provide an adequate microenvironment for lipase action, but also improve mass-transfer phenomena of hydrophobic substrates and products from the $\mathrm{scCO}_{2}$ phase, leading to a highly active and selective immobilized enzyme, stable even at high temperatures and pressures.

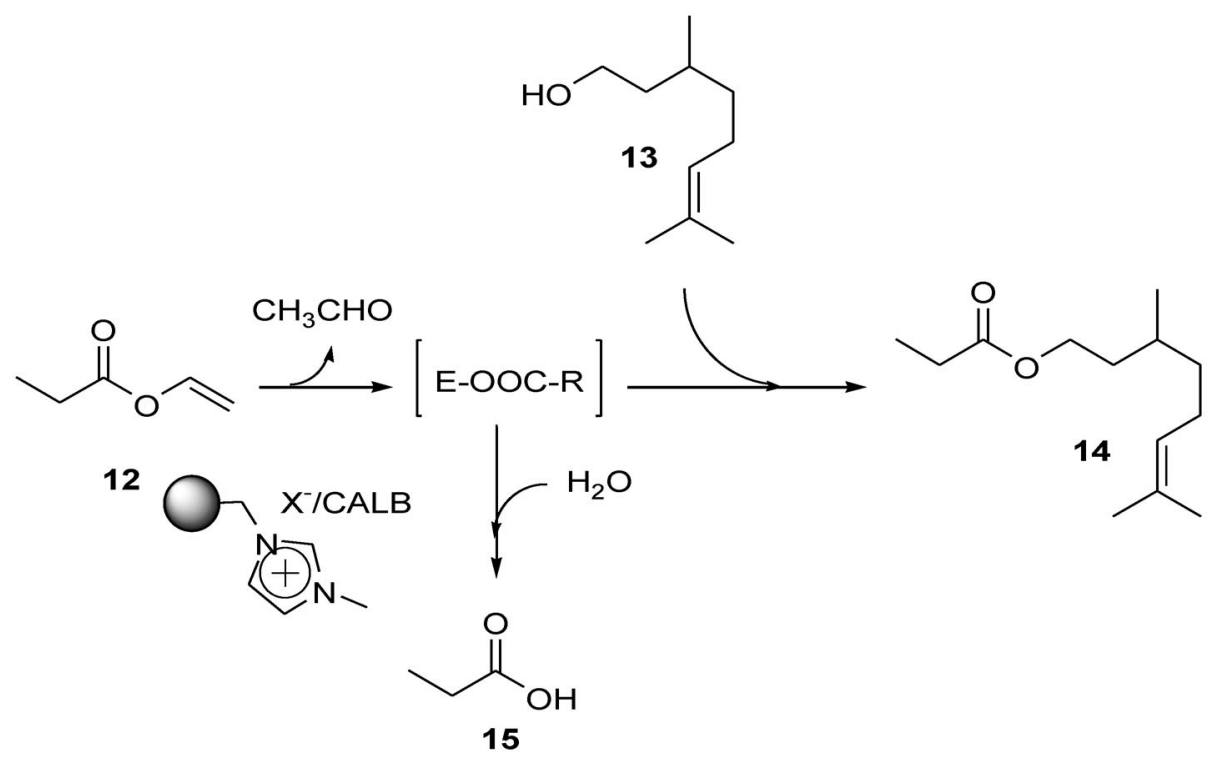

Scheme 4 Continuous citronellyl propionate synthesis in $\mathrm{scCO}_{2}$.

Table 1 Experimental conditions and product yields obtained for the synthesis of $\mathbf{1 4}$ in $\mathrm{scCO}_{2}$ at $10 \mathrm{MPa}$ catalyzed by the $m$-SILLP-11 containing immobilized CALB.

\begin{tabular}{lcccccc}
\hline Entry & $\begin{array}{c}\text { Temp. } \\
\left({ }^{\circ} \mathrm{C}\right)\end{array}$ & $\begin{array}{c}\mathrm{CO}_{2} \\
\text { density } \\
(\mathrm{g} / \mathrm{ml})\end{array}$ & $\begin{array}{c}\text { Inlet } \\
\text { mass } \\
\text { flow } \\
(\mu \mathrm{mol} / \mathrm{min})\end{array}$ & $\begin{array}{c}\text { Operation } \\
\text { time }(\mathrm{h})\end{array}$ & & \multicolumn{2}{c}{ Yield $(\%)$} & \\
\cline { 5 - 7 } & & & 10 & 10 & $55.7 \pm 2.6$ & $1.6 \pm 0.2$ \\
\hline 1 & 40 & 0.627 & 10 & 10 & $86.2 \pm 2.0$ & $<0.1$ \\
2 & 60 & 0.301 & 20 & 10 & $92.8 \pm 3.2$ & $<0.1$ \\
3 & 80 & 0.226 & 40 & 5 & $24.3 \pm 3.8$ & $<0.1$ \\
4 & 100 & 0.191 & 20 & & & \\
\hline
\end{tabular}

\section{Basic IL-like phases as catalysts for the Henry reaction}

As mentioned above, the exchange of the original chloride counteranion in monoliths 4 by other counteranions is a simple and efficient procedure that can be achieved in a quantitative way. This enables the supporting of anions that could participate as reagents or catalysts for different chemical 
processes. The simplest case is that in which the corresponding supported acetate or hydroxide is prepared. The corresponding supported bases (i.e., 16) have shown to be able to participate in base-catalyzed reactions [41]. This is illustrated in the case of the Henry reaction between nitromethane and $p$-nitrobenzaldehyde (Scheme 5). The reaction can be carried out under solventless conditions, using an excess of nitromethane. Using a continuous flow set-up, the excess of nitromethane can be easily recovered at the end of the process and reused being fed back to the reaction. Under those conditions, more than $95 \%$ yield of the corresponding nitroalcohol $\mathbf{1 8}$ was obtained for ca. 50 bed volumes. Deactivation of the supported catalyst seems to occur through metathesis of the catalytic anion by other organic anions formed in the course of the Henry reaction. Nevertheless, reactivation can be easily achieved just by incorporating an intermediate process, under the same flow conditions, of basic washing after a given number of bed volumes (i.e., $40-50$ bed volumes).

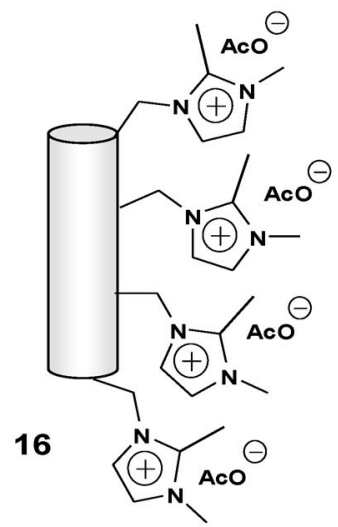<smiles>[R]C([3H])[N+](=O)[O-]</smiles>

Scheme 5 Use of basic SILLPs for the continuous Henry reaction.

It is interesting to note that very high productivities can be achieved using this experimental setup under flow conditions. One of these microreactors, having a free-volume of 500-800 $\mu$, is able to produce up to $3 \mathrm{~g}$ of product after $4-5 \mathrm{~h}$ of reaction, with residence times of a few minutes (1-7 min).

\section{CONCLUSIONS}

In summary, we have developed new $m$-SILLPs containing covalently attached IL-like moieties, so that the desired properties of the liquid are transferred to the surfaces of the solid support. Those $m$-SILLPs can be used as highly efficient supports for the noncovalent immobilization of either Pd(0)-NPs, enzymes, or basic catalysts. The resulting catalytic systems can be used as reactors for the Heck or lipasecatalyzed ester synthesis in SCFs and used for the Henry reaction under solventless conditions. In the first two cases, the high efficiency of the systems was dependent on both the microenvironment provided by the support and the supercritical conditions, which are involved in the mass-transfer phenomena. The methodology here reported represents a simple and straightforward strategy to improve the efficiency of a catalytic reaction under nonclassical conditions, allowing the development of green synthetic chemical processes. Catalytic performances are similar or even better than those obtained for batch conventional systems and can be even superior to those found for the homogeneous counterparts [42]. Our current efforts are directed toward the analysis of the scope of the application of the former catalytic systems for a variety of synthetic transformations, including additional variables to be considered, in particular, chirality. 


\section{ACKNOWLEDGMENTS}

Financial support has been provided by the Spanish Ministerio de Ciencia y Tecnología (CTQ 200508016), Generalitat Valenciana (GV ARVIV/2007/081), and Bancaixa-UJI (P1B2004-13) for financial support. E. G.-V. thanks MCYT for personal financial support (Ramón y Cajal program).

\section{REFERENCES}

1. T. Welton. Chem. Rev. 99, 2071 (1999).

2. R. D. Rogers, K. R. Seddon (Eds.). Ionic Liquids as Green Solvents: Progress and Prospects, ACS Symposium Series 856, American Chemical Society, Washington, DC (2003).

3. See monographic issue: Acc. Chem. Res. 40, 1078 (2007).

4. P. Wasswescheid, T. Welton (Eds.). Ionic Liquids in Synthesis, $2^{\text {nd }}$ ed., Wiley-VCH, Weinheim (2007).

5. J. Ranke, S. Stolte, R. Störmann, J. Arning, B. Jastorff. Chem. Rev. 107, 2183 (2007).

6. C. P. Mehnert. Chem.-Eur. J. 11, 50 (2005).

7. Y. Gu, A. Karma, F. Jérôme, J. Barrault. Org. Lett. 9, 3145 (2007).

8. H. Hagiwara, K. H. Ko, T. Hoshi, T. Suzuki. Chem. Commun. 2838 (2007).

9. M. Haumann, K. Dentler, J. Joni, A. Riisager, P. Wassercheid. Adv. Synth. Catal. 349, 425 (2007).

10. Y. Gu, C. Ogawa, S. Kobayashi. Org. Lett. 9, 175 (2007).

11. D. W. Kim, D. J. Hong, K. S. Jang, D. Y. Chi. Adv. Synth. Catal. 348, 1719 (2006).

12. B. Karimi, D. Enders. Org. Lett. 8, 1237 (2006).

13. W. Chen, Y. Zhang, L. Zhu, J. Lan, R. Xie, J. You. J. Am. Chem. Soc. 129, 13879 (2007).

14. Y. Xie, Z. Zhang, T. Jiang, J. He, B. Han, T. Wu, K. Ding. Angew. Chem., Int. Ed. 46, 7255 (2007).

15. J. Y. Shin, B. S. Lee, Y. Jung, S. J. Kim, S.-g. Lee. Chem. Commun. 5238 (2007).

16. D.-H. Lee, J.-H. Kim, B.-H. Jun, H. Kang, J. Park, Y.-S. Lee. Org. Lett. 10, 1609 (2008).

17. P. T. Anastas, M. M. Kirchhoff, T. C. Williamson. Appl. Catal. A 221, 3 (2001).

18. A. Kirschning, W. Solodenko, K. Mennecke. Chem.-Eur. J. 12, 5972 (2006).

19. B. Altava, M. I. Burguete, J. M. Fraile, J. I. García, S. V. Luis, J. A. Mayoral, M. J. Vicent. Angew. Chem., Int. Ed. 39, 1503 (2000).

20. M. J. Fernández, J. M. Fraile, J. I. García, J. A. Mayoral, M. I. Burguete, E. García-Verdugo, S. V. Luis, M. A. Hammer. Top. Catal. 13, 303 (2000).

21. M. I. Burguete, E. García-Verdugo, M. J. Vicent, S. V. Luis, H. N. Pennemann, N. G. Keyserling, J. Martens. Org. Lett. 4, 3947 (2002).

22. A. Cornejo, J. M. Fraile, J. I. García, M. J. Gil, G. Legarreta, S. V. Luis, V. Martínez-Merino, J. A. Mayoral. Org. Lett. 4, 3927 (2002).

23. J. M. Fraile, E. García-Verdugo, S. V. Luis, V. Martinez, J. A. Mayoral. Ind. Eng. Chem. Res. 44, 8580 (2005).

24. A. Cornejo, J. M. Fraile, J. I. García, M. J. Gil, S. V. Luis, V. Martinez, J. A. Mayoral. J. Org. Chem. 70, 5536 (2005).

25. B. Altava, M. I. Burguete, E. García-Verdugo, S. V. Luis, M. J. Vicent. Green Chem. 8, 717 (2006).

26. M. I. Burguete, A. Cornejo, E. García-Verdugo, M. J. Gil, S. V. Luis, J. A. Mayoral, V. MartínezMerino, M. Sokolova. J. Org. Chem. 72, 4344 (2007).

27. M. I. Burguete, A. Cornejo, E. García-Verdugo, J. García, S. V. Luis, J. A. Mayoral, V. MartínezMerino, M. Sokolova. Green Chem. 9, 1091 (2007).

28. FT-IR: B. Altava, M. I. Burguete, E. García-Verdugo, S. V. Luis, M. J. Vicent. Tetrahedron 57, 8675 (2001).

29. FT-Raman: B. Altava, M. I. Burguete, E. García-Verdugo, S. V. Luis, M. J. Vicent. Tetrahedron Lett. 42, 8459 (2001). 
30. For the NBP test, see: F. Galindo, B. Altava, M. I. Burguete, R. Gavara, S. V. Luis. J. Comb. Chem. 6, 859 (2004).

31. P. Bosch, F. Catalina, T. Corrales, C. Peinado. Chem.-Eur. J. 11, 4314 (2005).

32. M. I. Burguete, F. Galindo, E. García-Verdugo, N. Karbass, S. V. Luis. Chem. Commun. 3086 (2007).

33. F. Svec, J. M. J. Frechet. Science 273, 205 (1996).

34. M. Weck, C. W. Jones. Inorg. Chem. 46, 1865 (2007).

35. B. Altava, M. I. Burguete, E. García-Verdugo, N. Karbass, S. V. Luis, A. Puzari, V. Sans. Tetrahedron Lett. 47, 2311 (2006).

36. M. T. Reetz, E. Westermann. Angew. Chem., Int. Ed. 39, 165 (2000).

37. A. M. Caporusso, P. Innocenti, L. A. Aronica, G. Vitulli, R. Gallina, A. Biffis, M. Zecca, B. Corain. J. Catal. 234, 1 (2005).

38. N. Karbass, V. Sans, E. García-Verdugo, M. I. Burguete, S. V. Luis. Chem. Commun. 3095 (2006).

39. T. De Diego, P. Lozano, S. Gmouh, M. Vaultier, J. L. Iborra. Biomacromolecules 6, 1457 (2005).

40. P. Lozano, E. García-Verdugo, R. Piamtongkama, N. Karbass, T. De Diego, M. I. Burguete, S. V. Luis, J. L. Iborra. Adv. Synth. Catal. 349, 1077 (2007).

41. M. I. Burguete, H. Erythropel, E. García-Verdugo, J. García, S. V. Luis, V. Sans. Green Chem. 10, 401 (2008).

42. B. Altava, M. I. Burguete, E. García-Verdugo, S. V. Luis, M. J. Vicent, J. A. Mayoral. React. Funct. Polym. 48, 25 (2001). 